\title{
Evaluating the University of North Texas' Digital Collections and Institutional Repository: An Exploratory Assessment of Stakeholder Perceptions and Use
}

\author{
Laura Waugh $^{\mathrm{a}}$, Jesse Hamner ${ }^{\mathrm{a}}$, Janette Klein ${ }^{\mathrm{b}}$, Sian Brannon ${ }^{\mathrm{a}}$ \\ ${ }^{a}$ UNT Libraries, 1155 Union Circle Drive \#305190, University of North Texas, Denton, TX \\ 76203-5017, USA \\ ${ }^{b}$ UNT College of Information, 1155 Union Circle Drive \#311068, University of North Texas, \\ Denton, TX 76203-5017, USA
}

\begin{abstract}
The University of North Texas (UNT) Libraries conducted a study on the value of the UNT Digital Library, including its UNT Scholarly Works institutional repository, to investigate the value of the UNT Libraries' digital repositories as perceived by UNT faculty, staff, and graduate students. This evaluation of the impact of the UNT Libraries'interventions begins a longitudinal view of the overall impact of these digital repositories in order to inform decisions and provide baseline measurements against which future assessment results can be compared. Findings include that an increase in awareness of the UNT Libraries' digital repositories is statistically associated with a greater likelihood of multiple types of use and contributions back to digital repositories. Also, graduate students are, as a whole, more likely to be aware of and use the UNT Libraries' digital repositories than faculty or staff.
\end{abstract}

Keywords: Digital libraries; Institutional repositories; User studies.

\section{Introduction}

Academic libraries are increasingly required to demonstrate their value to institutional stakeholders and their impact on institutional missions (ACRL (Association of College and Research Libraries), 2010, Bankier \& Smith, 2010, Tenopir, 2013). The scope and content of the scholarly resources within academic libraries' digital repositories directly relate to satisfying these requirements (Fox, 2011). Rapid expansion in web-based technology over the last three decades has led to growth in digital library services and collections. Much of the early research on digital library evaluation focused on system infrastructure and user access (Fuhr et al., 2007). Research concerning the value of digital repositories often concerns repository development, either within a country or at a university, and the challenges of gaining stakeholders' commitment to contribute their scholarly outputs to their institutional repositories (IRs). These remain important issues, but equally so are measures of effectiveness and overall value.

The University of North Texas (UNT) has been on the forefront of mass-digitization and repositories since the creation of the Digital Library Division in 2004. As one of only three universities to serve as an affiliated archive of the National Archives and Records Administration in the United States, and with over 2.5 million newspaper pages digitized, the UNT Digital Library ranks among the top 25 world repositories (Top Institutional, 2014). Ideas for a statewide portal of Texas history and information began in the early 2000s. Grants for establishing the infrastructure and ingesting content helped The Portal to Texas History grow to become one of 
the most visited sites in the university's web presence. In 2010, UNT began its institutional repository, called UNT Scholarly Works, in response to the institution's newly created Open Access Policy (UNT (University of North Texas) Open Access Policy, 2012).

Although many statistical indicators are measured internally, such as webpage hits, item downloads, and number of contributing partners, there has been only one formal assessment as to the use of UNT digital collections to date. That study focused specifically on The Portal to Texas History, and found that the collection has a cultural and economic impact on its users, allowing them to access freely-available historical materials for research and personal use (Belden \& Murray, 2012).

The objective of the present study is to investigate the value of the UNT Libraries' digital repositories as perceived by UNT faculty, staff, and graduate students. Research questions include:

1. Is there a relationship between the perceived value of the UNT Digital Library or UNT Scholarly Works and awareness of these resources by UNT faculty, staff, and graduate students?

2. Is there a relationship between the perceived value of the UNT Digital Library or UNT Scholarly Works and contributions to these resources by UNT faculty, staff, and graduate students?

3. Is there a relationship between the perceived value of the UNT Digital Library or UNT Scholarly Works and use of these resources in coursework or scholarship by UNT researchers?

4. Are there differences between the perceived value of, or contributions to, the UNT Digital Library or UNT Scholarly Works and the respondent's university positions, department, age groups, gender?

\section{Operational Definitions}

Because of the abstract nature of many terms in the research questions, the authors provide these operational definitions and measurement techniques.

Value of the UNT Libraries' digital repositories includes faculty, staff, and graduate students' attitudes toward the repositories and their use of the resources in the repositories, expressed as Likert scale agreement or disagreement with a battery of questions.

Awareness includes the degree of familiarity with specific digital repositories and collections (e.g., UNT Digital Library, UNT Scholarly Works repository) and recognition of the resources (collections) contained within the UNT Libraries' digital repositories.

Contributions to UNT Libraries' digital repositories are scholarly products produced by faculty, staff, and graduate students, measured by the cumulative number of items (i.e., papers, 
presentations, posters, images, and other item types) submitted for inclusion in the UNT Scholarly Works repository.

Use is reflected in scaled responses regarding the number of citations to resources in the UNT Digital Library and its UNT Scholarly Works repository. Additionally, "use" includes the likelihood that faculty, staff, and graduate students will contribute to the UNT Scholarly Works repository, and the likelihood that faculty will incorporate UNT Digital Library resources in their coursework.

Scholarly Outputs include the number of publications, presentations, performances, and patents in the previous two years by type, including journal articles, books, book chapters, book reviews, edited books or anthologies, and presentations at professional conferences.

Interest is the expected future contribution of scholarly outputs to the UNT Libraries' digital repositories by faculty, staff, and graduate students, expressed in a series of Likert-scaled questions and free-form answers about the respondents' interest in contributing to the UNT Scholarly Works repository collection.

\section{Literature Review}

Demonstrable value to the institutional stakeholders and evidence of impact upon the institutional mission are increasingly being required by academic libraries (ACRL (Association of College and Research Libraries), 2010, Bankier \& Smith, 2010 and Tenopir, 2013). Within the academic libraries' digital repository, the scope and content of scholarly resources directly relate to satisfying these requirements (Bankier and Smith, 2010, Fox, 2011, Kim, 2007). While Markey, Reih, St. Jean, Yakel, and Xingxing (2009) emphasized content recruitment as a critical component to the fundamental premise of Institutional Repositories (IR), they also noted that external success factors of an IR include a direct relationship between the institutional and/or library goals and successful use of IR content by users. Research surrounding the value of digital repositories often concerns measurement of repository development, the challenges of gaining stakeholders' commitment to contribute to their scholarly outputs to IRs, copyright and preservation issues, and IR promotion and marketing (Covey, 2011, Creaser, 2010, Cullen \& Chawner, 2011).

Cullen and Chawner (2010) conducted an initial investigation of repository users and repositories in New Zealand and discovered that users were more interested in externally developed, discipline-specific repositories than in repositories housed at their own institutions. In fact, the authors find that institutions struggle to gain their own researchers' commitment to contribute their scholarly outputs to repositories. A subsequent study conducted by Cullen and Chawner (2011) revealed that ongoing barriers to depositing in IRs include faculty and IR staff workload, challenges of IR use, lack of awareness, and concerns of data confidentiality. Barriers such as these contributed to the ongoing low rates of IR deposits, yet were perceived as offering unique opportunities for IR managers to reposition themselves as valuable resource centers for scholarly communication. IR managers during the repositioning process were encouraged to also seek alternate content types for inclusion in the IR, strengthen metadata, and review the IR technical infrastructure to more robustly support existing IR content. 
Tripathi and Jeevan (2011) found similar results in India, where institutional repositories faced a huge problem with low quantities of scholarly submissions from researchers. An investigation of Malaysian repositories supports this finding, but suggests that when librarians take an active role in repository collection development and marketing, the number of submissions improves (Kamraninia and Abrizah, 2010). An institutional survey administered by Creaser (2010) to academic institutions located in the UK assessed the impact of open access and self-archiving on IRs scholarly communication outputs from the research process. Findings indicated that although over half of the responding institutions had mandates in place for deposits to the IR, over half of the researchers participating in the survey did not know the position of their institution on selfarchiving and were also unaware of institutional support for self-archiving to the IR. Conversely in Croatia, while the number of repositories is relatively low, there is great interest and awareness of institutional open access repositories and their benefits among librarians (Grgic and Barbaric, 2011).

At the University of Maryland (UMD), Owen (2011) researched the development of the IR and the changes in scope that proved invaluable in the IR development process. The UMD IR was intended as a means to collect faculty-published articles; however, when faced with faculty reluctance to contribute articles, IR scope was expanded to house grey literature as well as graduate and undergraduate research. This facilitated IR population, in addition to addressing the needs of the wider UMD community in a more comprehensive manner. Nneka Eke (2011) investigated the challenges with scholarly content digitization and populating the institutional repository at the University of Nigeria. There was a great deal of interest at their university, but findings revealed that financial constraints and legal issues were the greatest hindrances to populating their institutional repository.

Research at Carnegie Mellon (Covey, 2011) focused on motivators for self-archiving in IRs as the need for ongoing IR deposits is necessary for the IR to be perceived as valuable by its users. Findings noted included factors such as IR awareness, alignment of deposits with existing workflows, and provision of value-added services as being important motivators for selfarchiving. Covey indicated that faculty still prefer to self-archive on websites over archiving in the IR. Barriers to the self-archiving process included issues of copyright and publisher policies, and the perception that discoverability and/or access was not a concern within certain disciplines (Covey, 2011). Three groups were identified that remain unrealized potential depositors to the IR: those who already archive either on a personal website or a discipline specific IR, those who remain uninterested in self-archiving in any form, and those who as of yet have an unclear understanding of the legality and copyright issues surrounding self-archiving. Similarly, a study of Texas A\&M University faculty (Yang and Li, 2015) found lack of awareness of the IR and the deposit process, concerns about copyright and publisher policies, and a perception of lower quality and less prestigious items in the IR to be barriers in IR participation.

Dubinsky (2014) conducted a mixed method study of IRs utilizing the Digital Commons platform hosted by Berkeley Electronic Press to determine "disciplinary scope of faculty content and to measure the growth rate of IR content" (p. 1). Although the study found that the IR growth rate was increasing, the rate of increase was inconsistent across IRs. It was also noted that discipline-specific contributions to the IR were heavily focused in the Sciences as compared 
to those made from the Humanities or Social Sciences. IR administrators engaged faculty to procure and mediate IR deposits from faculty while IR administrators also promoted ongoing active engagement to market the "existence, purpose, and benefit" of the IR (p. 18) which are still perceived as necessary to bolster the nominal contributions by faculty within the Humanities and Social Science disciplines. Dubinsky cautioned that it may be time to reassess the purpose of the IR and evaluate IR content by type in relation to the institutional mission and goals in order to better align the IR with the institutional goals and mission (p. 18). This finding mirrors the study performed by Nicholas et al. (2013), as part of the Charleston Observatory, which investigated library director perceptions of IR success, identification of IR goals, and impact assessment of the IR. The study found that over half of the IRs reviewed were looking to implement deposit mandates to bolster flagging deposit rates. Of the six IR success factors identified within the study, the respondents identified attraction of both material for the IR, and users for the existing IR material as a primary key indicators of success. Ongoing concerns by library directors and IR depositors still exists surrounding copyright issues and general awareness of the purpose of the IR.

Kim (2007) developed a model utilizing the socio-technical interaction network (STIN) model and social exchange theory to determine factors influencing faculty self-archiving to the institutional repository. The pilot study conducted by Kim (2007) tested the feasibility of the proposed model by analyzing the "relationships between costs, perceived intrinsic and extrinsic benefits, individual characteristics, and contextual factors" (para. 12) of faculty self-archiving behaviors. Although statistically significant findings could not be drawn from the pilot study due to its small scale, the preliminary finding that benefit factors appeared to have greater impact than those of cost or contextual factors served as an impetus for further research. A subsequent one-year study drawing upon 17 universities selected from the DSpace federation listing concluded in 2007 (Kim, 2010). The parameters of the subsequent study were not limited to faculty self-archiving in the IR but also included faculty self-archiving practices through other outlets including personal websites, department websites, and open access outlets. Findings indicated that significant factors to self-archiving include altruism, the self-archiving culture, copyright concerns, technical skills and age, impact of self-archiving on tenure and promotion, and the impact of self-archiving upon existing workflows. Kim (2011) further refined the analysis of these two previous studies performed in 2007 and 2010 by reviewing faculty selfarchiving motivations within IRs and found that these were affected by accessibility both for archived content to be accessible to others and as a form of scholarly communication with peers, altruism, trust, and copyright concerns (pp. 250-251).

Dorner and Revell (2012) utilized Rogers' Diffusion of Innovations theory in a qualitative study of New Zealand IRs and their rate of adoption as perceived by subject librarians. The study focused on measurement of IR success by the deposits made, through the user perception of accessibility and inclusion of usable content. Bankier and Smith (2010) investigated outreach programs in Australia focusing on the need for the IR to be a centralized focus of scholarly life and contributions. Their study also reviewed actions undertaken by academic libraries to move IR acceptance forward. They found that that mandates to deposit scholarly outputs, while acceptable and in many cases understandable, do not truly increase value either to the faculty or to stakeholders. They also indicated that the IR should have a role of "serving" academia and the community rather than that of policing content. IRs have the potential to provide diversified 
services which better fit with the goals, mission and role of the university, while also providing expanded outreach to realized and potential users. This finding, though narrow in scope, substantiates earlier work by Lynch (2003) which indicated that although there is potentially great benefit to institutional repositories both as a collaborative initiative with existing publishing paradigms and as a new venue for scholarly outputs, there are many potential reasons that an IR will not succeed including those of policy issues, IR management deficiencies, technical systems issues related to the harvesting, maintenance and support of the IR, and also deficiencies in the preservation of archived content.

This investigation moves beyond previous studies that focus primarily on early repository development and the challenges of gaining faculty support, instead examining the impact and value of UNT Libraries' existing digital repositories for key stakeholder groups in the UNT community, two areas of great importance to both UNT and the digital repository field as a whole. The results of this initial assessment will inform decisions and interventions on the part of the UNT Libraries and will provide baseline measurements against which future assessment results can be compared, thus providing both an evaluation of the impact of the UNT Libraries' interventions and a longitudinal view of the overall impact of these digital repositories.

\section{Research Design}

The University of North Texas (UNT) Libraries conducted a study to measure the perceived value of the UNT Digital Library and its UNT Scholarly Works collection. A Qualtrics survey based on the original research questions was created and included quantifiable questions for data The University of North Texas (UNT) Libraries conducted a study to measure the perceived value of the UNT Digital Library and its UNT Scholarly Works collection. A Qualtrics survey based on the original research questions was created and included quantifiable questions for data collection. The survey asked a series of related questions to establish metrics for measuring value based on respondents' awareness, use of, and interest in the UNT Libraries digital repositories.

The survey instrument was validated by two researchers on the project team using cognitive interviewing techniques. Prior to administering the survey, a small group of UNT faculty, staff, and graduate students were asked to take the survey in a controlled environment with two researchers present. The sample group provided synchronous verbal feedback as they took the survey to ensure accuracy and further validate the questions asked. The survey instrument, data, and codebook can be found in the UNT Data Repository (Waugh, Murray, Phillips, and Belden, 2013).

The survey was offered to all currently employed or enrolled UNT faculty, staff, and graduate students as of the fall 2013 semester. Information was obtained with approval from the UNT Institutional Review Board (IRB), the UNT Human Resources Department, and the UNT Toulouse Graduate School. A total of 11,678 UNT faculty, staff, and graduate students were contacted to participate in this study. A total of 785 responded to the email survey, a response rate of $6.7 \%$. The survey included filter questions, and not every participant was asked every question. The filter questions differentiated participants based on their employment rank, whether they teach courses, and whether they utilize research resources as part of their coursework or employment rank. 


\section{General Results}

This study of the UNT Digital Library and UNT Scholarly Works collection is an explorative effort to establish baseline measurements for determining the perceived value of the collections as related to awareness of and contributions to them. The descriptive demographic breakdown of the respondents is represented in Table 1 below:

\begin{tabular}{|l|r|}
\hline Gender $(\mathrm{n}=589)$ & \\
\hline Female & $61 \%$ \\
\hline Male & $39 \%$ \\
\hline & \\
\hline$\underline{\text { Age }(\mathrm{n}=591)}$ & $6.6 \%$ \\
\hline $18-24$ & $30.6 \%$ \\
\hline $25-34$ & $21.3 \%$ \\
\hline $35-44$ & $23 \%$ \\
\hline $45-54$ & $13.9 \%$ \\
\hline $55-64$ & $4.6 \%$ \\
\hline 65 or over & \\
\hline & $1 \%$ \\
\hline Highest Education Level Attained $(\mathrm{n}=621)$ & \\
\hline High school & $3.9 \%$ \\
\hline Some college & $1.2 \%$ \\
\hline Vocational/Technical/Associate's & $15 \%$ \\
\hline Bachelor's degree & $19.1 \%$ \\
\hline Some graduate courses & $36.9 \%$ \\
\hline Master's degree & $22.9 \%$ \\
\hline Doctoral/Professional degree & \\
\hline
\end{tabular}

Table 1: General information about respondents

Table 2 below highlights information about the respondents related to their responsibilities at the university and their reported academic disciplines. Categories for academic disciplines were loosely based on taxonomies of the "Classification of Instructional Programs," last revised by the National Center for Education Statistics in 2010 (https://nces.ed.gov/ipeds/cipcode/).

\begin{tabular}{|l|r|}
\hline Position $(\mathrm{n}=618)$ & \\
\hline Graduate student & $44.5 \%$ \\
\hline Staff & $26.9 \%$ \\
\hline Faculty & $20 \%$ \\
\hline Administrator & $5.7 \%$ \\
\hline Non-faculty/Other & $2.9 \%$ \\
\hline & \\
\hline Job Responsibilities Include... & $37 \%$ \\
\hline Teaching university courses $(\mathrm{n}=616)$ & \\
\hline
\end{tabular}




\begin{tabular}{|l|r|}
\hline Research (n=620) & $64 \%$ \\
\hline Associated Academic Discipline (n=487) & \\
\hline $\begin{array}{l}\text { Professions and Applied sciences (Education, business, engineering, } \\
\text { family science, public administration) }\end{array}$ & $32.5 \%$ \\
\hline Library and museum studies & $24.4 \%$ \\
\hline Humanities (Linguistics, literature, arts, philosophy, history, religion) & $21.8 \%$ \\
\hline $\begin{array}{l}\text { Social sciences (Cultural/ethic studies, economics, geography, political } \\
\text { science, psychology, sociology) }\end{array}$ & $11.3 \%$ \\
\hline $\begin{array}{l}\text { Formal and natural sciences (Mathematics, biology, chemistry, physics, } \\
\text { earth science, computer science, systems and logic) }\end{array}$ & $10 \%$ \\
\hline
\end{tabular}

Table 2: University responsibilities and academic disciplines.

\section{Analysis}

The set of respondents are considered in the aggregate, accounting for characteristics of each respondent that may represent a tendency for groupings by variables such as faculty, staff, or graduate student status, gender, age category, or other independent variables as listed below. The unit of analysis here is the individual. At present, the survey has been conducted only once, and therefore these data are cross-sectional but not longitudinal.

Control variables included basic demographics, academic discipline and major field of study, university role/employment, research productivity, and education. The primary outcome (dependent) variable is some variant of an individual's valuation of the UNT Digital Library or UNT Scholarly Works repository collection, such as willingness to contribute academic work to the repository, assigning resources contained in the UNT Digital Library as coursework, or even factoring these resources in to a personal employment decision. A series of models using the same basic parameters were run, each using a variable measuring some operationalized definition of the following: awareness of the UNT Digital Library, awareness of the UNT Scholarly Works collection, personal valuation of a generic digital library, personal valuation of a scholarly works repository, contribution to the UNT Digital Library collections, or contribution to the UNT Scholarly Works collection.

Additional independent variables are included in each model, including basic demographics such as gender (dichotomous in this survey), age group (ordinal), and status as a UNT faculty member, graduate student, or staff. Staff status is used as the reference category for occupation when performing numerical analyses. Some models replace the individual's employment status with faculty category (non-tenure-track, tenure-track but untenured, and tenured). Some models include the individual's academic discipline, broadly categorized into social sciences, physical/natural sciences, humanities, information sciences, and "other." The different measures of "awareness" and "contributions," with very few exceptions, had little difference in effect on the outcome variable. That is, different measures of the same notion such as "awareness of the UNT Digital Library" seem to effectively measure the same underlying concept in this sample of respondents. 
Numerical analyses conducted using R version 3.1 (R Core Team, 2014) included ordered logistic regression ("ordinal logit") and standard dichotomous logistic regression ("logit"). Ordinal logistic regressions are robust and flexible, and despite the assumption that the distance between each category in the outcome is proportional, remain useful and flexible where the parallel regression assumption is violated. Ordinal logit provides a good balance between evaluating the likelihood of moving from one Likert category to another, but maintaining parsimony in the model and not discarding information by either collapsing categories to a strict binary value (as one does with a standard logit), or by using a multinomial logit (that assumes responses are unordered, but does not require a proportional distance between each ordered outcome value). With a relatively small $\mathrm{N}$ as we have in this set of data, including only a small set of independent variables increases the ability of the regression to provide useful and valid results.

Raw coefficients from the regressions are converted into more easily parsed odds ratios. That is, we convert the log-likelihood of each independent variable being associated with a shift in the dependent variable category or value into a number that can be expressed as "number of times more or less likely than a reference category having that same value." Odds ratios near 1.0 reflect no change in the likelihood of moving to a higher or more intense category. Statistically significant odds ratios smaller than 1.0 reflect a decrease in the likelihood of moving to a higher or more intense category, and ratios larger than 1.0 reflect an increase in the likelihood of moving to a higher or more intense category. Thus, as seen in Table 3, an odds ratio of 4.3 for the Graduate Student status variable should be interpreted as meaning graduate students are over four times more likely to consider the UNT Digital Library to be relevant (or more relevant) to their work than someone in a reference category (here, staff). In this study, p-values of $<0.05$ are considered statistically significant.

Variable
\begin{tabular}{|l|l|l|}
\hline Faculty Status & 1.90 & 0.00 \\
\hline Graduate Student Status & 2.17 & 0.00 \\
\hline Age Category & 0.98 & 0.82 \\
\hline Male (dichotomous) & 1.02 & 0.92 \\
\hline
\end{tabular}

Table 3: University responsibilities and academic disciplines.

\section{Discussion}

Research question 1: Is there a relationship between the perceived value of the UNT Digital Library or UNT Scholarly Works and awareness of these resources by UNT faculty, staff, and graduate students?

The mean familiarity of respondents with the UNT Digital Library was 2.8 out of 5. In Table 3, compared to the reference category of "staff", analysis showed that faculty are 1.90 times more likely to be aware of the UNT Digital Library. Graduate students are more likely to be aware of the UNT Digital Library compared to staff, and slightly more likely than faculty. While the results are not surprising, it is helpful to see the magnitude of the difference, and to see that current UNT graduate students are aware of the UNT Digital Library, compared to faculty and 
staff at present, with a significance level of $\mathrm{p}<0.001$. Students responding to open-ended questions indicate that they value the digital materials for their online and distance-learning coursework. While some faculty reported that they weren't aware of the resources, they indicated that their value was apparent (even if the specific collections weren't necessarily important to their discipline.)

When considering the broad disciplines of the respondents, seen in Table 4, the value that the UNT Digital Library represents to constituent groups at UNT becomes more clear, but more varied. The natural sciences and the social sciences value the UNT Digital Library much less than their colleagues in the humanities. This finding is understandable, given the scope and coverage of the collections currently in the UNT Digital Library, but it also highlights a potential marketing opportunity in making the faculty in non-humanities disciplines more aware of what collections may be of use to them. Here again, it is easy to see the relatively greater value placed on digital resources by graduate students, even accounting for their discipline category.

Variable
\begin{tabular}{|l|l|l|}
\hline Faculty Status & 1.37 & 0.26 \\
\hline Graduate Student Status & 3.30 & 0.00 \\
\hline Age Category & 1.00 & 1.00 \\
\hline Male (dichotomous) & 1.30 & 0.21 \\
\hline Humanities & 2.59 & 0.08 \\
\hline Social Sciences & 0.60 & 0.05 \\
\hline Natural Sciences & 0.15 & 0.00 \\
\hline Professional/Applied Sciences & 1.03 & 0.94 \\
\hline
\end{tabular}

Table 4: Respondent's perception of relevance of the UNT Digital Library.

Perhaps the most extreme level of measuring an individual's estimation of the value of a digital library or institutional repository would be when considering an offer of employment. In Table 5 it can be seen that, at least when answering this survey, graduate students (nearly statistically significant), and those who were more aware of the variety of digital collections available through the UNT Digital Library (significant at $\mathrm{p}<0.05$ ), report that digital library and repository resources would affect their decision to accept an offer of employment from an institute of higher learning. Faculty status, age, gender, and all academic disciplines except the natural sciences have no association with this kind of personal valuation of digital library resources and services.

\begin{tabular}{|c|c|c|}
\hline Variable & Odds Ratio & p-value \\
\hline Faculty Status & 0.92 & 0.76 \\
\hline Graduate Student Status & 1.59 & 0.06 \\
\hline Age Category & 0.96 & 0.63 \\
\hline Male (dichotomous) & 0.92 & 0.68 \\
\hline Humanities & 0.57 & 0.15 \\
\hline Social Sciences & 0.73 & 0.22 \\
\hline
\end{tabular}




\begin{tabular}{|l|l|l|}
\hline Natural Sciences & 0.27 & 0.00 \\
\hline Professional/Applied Sciences & 0.85 & 0.69 \\
\hline
\end{tabular}

Table 5: Degree to which a respondent would consider an institution's digital resources and services in making an employment decision.

Research question 2: Is there a relationship between the perceived value of the UNT Digital Library or UNT Scholarly Works and contributions to these resources by UNT faculty, staff, and graduate students?

The overall mean response of participants expressing likelihood to contribute scholarly output to the UNT Scholarly Works Repository was 3.76 on a 5-point scale. Faculty are possibly more likely than staff, but since staff typically have a low scholarly output, this result is unremarkable.

But here again, graduate students are twice as likely as either faculty or staff to express a willingness to contribute academic outputs to a campus digital repository. Surprisingly, males are significantly more willing than females to express a willingness to contribute academic outputs. Unsurprisingly, as respondents declare a belief that their digital library is relevant, their expected willingness to contribute scholarly works to a digital repository also rises, though it is impossible to say which, if either, is a causal variable. Respondents indicated that both the UNT Digital Library and the UNT Scholarly Works Repository were important to the university's prestige, with a mean response of 6.14 out of 7 for each. Results also suggest that outreach to graduate students has been effective, while outreach to faculty has been less so. Given that those who have at least some awareness of the repository tend to value it, it is possible, though not certain, that the lower values assigned by some respondents stems from a lack of awareness. In fact, some responses to open-ended questions indicated that some respondents' first knowledge of the UNT Digital Library and its collections was gleaned through taking the survey itself.

Table 6 shows a second take on intent to contribute to the UNT Scholary Works repository, here including the general discipline of the respondent. The academic discipline is not associated with any change in the respondent's willingness to contribute to the repository.

\begin{tabular}{|c|c|c|}
\hline Variable & Odds Ratio & p-value \\
\hline Faculty Status & 1.22 & 0.47 \\
\hline Graduate Student Status & 1.64 & 0.04 \\
\hline Age Category & 1.00 & 0.95 \\
\hline Male (dichotomous) & 1.60 & 0.02 \\
\hline Humanities & 0.93 & 0.78 \\
\hline Social Sciences & 1.55 & 0.20 \\
\hline Natural Sciences & 1.63 & 0.28 \\
\hline Professional/Applied Sciences & 0.78 & 0.32 \\
\hline
\end{tabular}

Table 6: Analysis of relevance and likelihood of contribution to the repository. 
Of those that reported a lack of interest in contributing to the repository, respondents had a variety of responses. A theme in these responses indicated that since libraries already provide access to their research through vendor-curated electronic resources and databases, there was no need to contribute them to the university's repository. There was also a lack of understanding about publishing rights and whether or not a researcher could simultaneously have their publications in formal scholarly journals. Another consideration was from researchers in dance, theater, and fashion design, who indicated that while they were interested in contributing, the UNT Digital Library and UNT Scholarly Works Repository were not yet compatible with their kinds of scholarly outputs.

When asked specifically about contributing research data to a repository designed specifically for data, respondents became more proprietary, vehemently refusing to do so because sharing the data "allows other researchers to produce work at your expense" and allows "other people to run analyses and possibly publish based on data that I collected."

Research question 3: Is there a relationship between perceived value of the UNT Digital Library or UNT Scholarly Works and the use of these resources in coursework or scholarship by UNT researchers?

In determining the existence of a relationship between perceived value and use, Tables 7 and Table 8 provide some interesting insights. Table 7 shows that certain disciplines are strongly more likely to assign materials from the UNT Digital Library collections/repositories. Related to a baseline category (here, staff), it makes sense that each discipline would be much more likely than people who do not teach - and therefore have no syllabi-to include UNT Digital Library materials in their coursework (average response 1.66 out of 3 for the UNT Digital Library and 1.31 for the UNT Scholarly Works repository). The differences among disciplines is instructive. The "familiarity" opinion terms support the idea that the more strongly one is aware of the UNT Digital Library, the more likely they are to include these materials in a course. However, even if the respondent stated that they do not use the resources in coursework perhaps due to their discplines, some did point out that the collections still have value.

\begin{tabular}{|c|c|c|}
\hline Variable & Odds Ratio & p-value \\
\hline Age Category & 1.21 & 0.01 \\
\hline Male (dichotomous) & 1.56 & 0.03 \\
\hline Humanities & 5.29 & 0.00 \\
\hline Social Sciences & 3.16 & 0.00 \\
\hline Natural Sciences & 5.44 & 0.00 \\
\hline Professional/Applied Sciences & 2.10 & 0.01 \\
\hline
\end{tabular}

Table 7: Analysis of inclusion of materials in syllabi and familiarity with repository.

\begin{tabular}{|l|l|l|}
\multicolumn{1}{l}{ Variable } & \multicolumn{1}{l}{ Odds Ratio } & \multicolumn{1}{l|}{ p-value } \\
\hline Age & 0.93 & 0.26 \\
\hline Male (dichotomous) & 1.03 & 0.88 \\
\hline Humanities & 1.28 & 0.34 \\
\hline
\end{tabular}




\begin{tabular}{|l|l|l|}
\hline Social Sciences & 1.84 & 0.04 \\
\hline Natural Sciences & 1.83 & 0.08 \\
\hline Professional/Applied Sciences & 1.05 & 0.84 \\
\hline $\begin{array}{l}\text { Linear Term for "Familiarity with } \\
\text { the Digital Library" }\end{array}$ & 3.87 & 0.00 \\
\hline
\end{tabular}

Table 8: Analysis of familiarity with the UNT Digital

Library and citing works it contains.

Finally, Table 8 shows that familiarity with the UNT Digital Library is strongly associated with a respondent citing works it contains. Here, as in Table 7, faculty/graduate status is not included, since the relatively low level of research output from most staff would artificially inflate the "faculty" or "graduate student" category odds ratios. It appears that researchers in the social sciences are nearly twice as likely to cite materials in the UNT Digital Library collections, all else being equal. It is possible that, given a larger sample, it would push the odds ratio of those respondents from the natural sciences towards significance, but in this survey, the result only hints that they are as similarly inclined as the social sciences.

Research question 4: Are there differences between the perceived value of, or contributions to, the UNT Digital Library or UNT Scholarly Works and the respondent's university positions, department, age groups, gender?

In evaluating the last research question, it appears that, with one exception in Table 7, age is not associated with any changes in respondent valuation or use of the UNT Digital Library collections. Gender seems to be statistically related to use and willingness to contribute to the UNT Digital Library collections; male respondents were about one and a half times more likely than female respondents to report that they use or would contribute to the UNT Digital Library or UNT Scholarly Works collections. Interestingly, even though staff did not report as much use of the resources, the researchers did learn that some staff do utilize the UNT Digital Library collections for their hobbies, including reading and genealogy.

Graduate students are more enthusiastic about digital library resources across the board, compared to faculty and staff, even considering these resources in making employment decisions. Furthermore, these results are remarkable because of the current lack of tenure support for open access repositories. That is, it would make sense for tenured faculty to support open access as they do not need to meet tenure requirements, except possibly for Associate Professors to earn promotion to Professor. For graduate students to support digital libraries and open access repositories is a stronger statement than it might appear.

There are no consistent findings for a given discipline. This result is not a surprise since there appear to be no departmental or discipline-wide cultures of support for digital library resources, at this early stage. Because of certain long-established resources like arXiv.org, it is possible that we can see the impact of that repository in the responses from the natural sciences in this survey, but no clear connection exists. The next iteration of this survey may reveal a trend among specific disciplines at UNT, but the current results cannot speak to that possibility. 


\section{Conclusion}

As stated in the literature review above, previous research has called for more demonstration of the value of IRs through delineation of various performance indicators. The present study outlines the impact of these collections to our stakeholders and is a first step in validating future investments in digital collections, specifically the UNT Scholarly Works IR.

For the UNT Libraries specifically, there are implications in these findings that will allow us to target marketing efforts and plan for educational opportunities. As graduate students displayed more positive attitudes towards the UNT Scholarly Works repository, we will work harder in the future to foster exposure to these students as they are possibly future faculty. We acknowledge that our established faculty are not as receptive, and staff even less so. However, we will solicit faculty to concede and promote the collections in their course syllabi.

Based on the findings of this initial study, the UNT Libraries have identified specific academic disciplines that currently place less value on the digital repositories investigated. Respondents identifying with the humanities were inconsistent in their responses when compared to those in the sciences, and unsurprisingly, library and information science. As a result, while some faculty in the humanities are enthusiastic contributors to the UNT Scholarly Works IR, across all humanities faculty, there is no discernable impact. There is also a need to consider the unique scholarly outputs of disciplines such as theater and dance in order to effectively include these as viable contributions to the repository.

Future assessment of the UNT Libraries' digital repositories are anticipated every three to four years. As the UNT Digital Library and UNT Scholarly Works IR collection continue to grow, future studies will compare scholarly outputs of our target audiences with satisfaction and ease of use. We will also partake in a review of current course syllabi to determine the extent of faculty promotion of the collections. Externally, we would like to broaden this across different types of post-secondary institutions in various geographic locations.

\section{Acknowledgements}

Special thanks goes to Dr. Kathleen Murray for initiating this study and for continued guidance, support, and contributions to this research.

\section{References}

ACRL (Association of College and Research Libraries). (2010). Value of Academic Libraries: A Comprehensive Research Review and Report. Researched by Megan Oakleaf. Chicago: Association of College and Research Libraries. Retrieved from http://www.ala.org/acrl/sites/ala.org.acrl/files/content/issues/value/val_report.pdf 
Bankier, J. G. \& Smith, C. (2010). Digital Repositories at a crossroads: Achieving sustainable success through campus-wide engagement. VALA 2010 Conference Proceedings. Retrieved from http://www.vala.org.au/vala2010-proceedings/vala2010-session-6-bankier

Belden, D. \& Murray, K. (2012). Measuring the Impact of Preserving Digital Assets. IS\&T Archiving Conference Proceedings. Retrieved from http://digital.library.unt.edu/ark:/67531/metadc93306/

Covey, D. T. (2011). Recruiting content for the institutional repository: The barriers exceed the benefits. JODI: Journal of Digital Information, 12(3), 1-18. Retrieved from https://journals.tdl.org/jodi/index.php/jodi/article/view/2068/1757

Creaser, C. (2010). Open access to research outputs - Institutional policies and researchers' views: Results from two complementary surveys. New Review of Academic Librarianship, 16(1), 4-25. http://dx.doi.org/10.1080/13614530903162854

Cullen, R. \& Chawner, B. (2010). Institutional repositories: Assessing their value to the academic community. Performance Measurement and Metrics, 11(2), 131-147. doi:http://dx.doi.org/10.1108/14678041011064052

Cullen, R. \& Chawner, B. (2011). Institutional repositories, open access, and scholarly communication: A study of conflicting paradigms. Journal of Academic Librarianship, 37(6), 460-470. http://dx.doi.org/10.1016/j.acalib.2011.07.002

Dorner, D. G. \& Revell, J. (2012). Subject librarians' perceptions of institutional repositories as an information resource. Online Information Review, 36(2), 261-277. http://dx.doi.org/10.1108/14684521211229066

Dubinsky, E. (2014). A current snapshot of institutional repositories: Growth rate, disciplinary content and faculty contributions. Journal of Librarianship \& Scholarly Communication, 2(3), 1-22. http://dx.doi.org/10.7710/2162-3309.1167

Fox, R. (2011). Digital viability. OCLC Systems \& Services: International Digital Library Perspectives, 28(1), 6-13. http://dx.doi.org/10.1108/10650751211197022

Fuhr, N., Tsakonas, G., Aalberg, T., Agosti, M., Hansen, P., Kapidakis, S., Klas, C. P., Kovacs, L., Landoni, M. Micsik, A., Papatheodorou, C., Peters, C. \& Solvberg, I. (2007) Evaluation of digital libraries. International Journal of Digital Libraries, 8(1). http://dx.doi.org/10.1007/s00799-007-0011-z

Grgic, I. H. \& Barbaric, A. (2011). The future of open access in Croatia: A survey of academic and research libraries. Library Review, 60(2), 155-160. http://dx.doi.org/10.1108/00242531111113096 
Kamraninia, K. \& Abrizah, A. (2010). Librarians' role as change agents for institutional repositories: A case study of Malaysian academic libraries. Malaysian Journal of Library \& Information Science, 15(3), 121-133.

Kim, J. (2007). Motivating and impeding factors affecting faculty contribution to institutional repositories. JODI: Journal of Digital Information, 8(2), 7-7. Retrieved from https://journals.tdl.org/jodi/index.php/jodi/article/view/193/177

Kim, J. (2010). Faculty self-archiving: Motivations and barriers. Journal of the American Society for Information Science \& Technology, 61(9), 1909-1922. doi:10.1002/asi.21336

Kim, J. (2011). Motivations of faculty self-archiving in institutional repositories. Journal of Academic Librarianship, 37(3), 246-254. doi:10.1016/j.acalib.2011.02.017

Lynch, C. A. (2003). Institutional repositories: Essential infrastructure for scholarship in the digital age. Portal: Libraries \& the Academy, 3(2), 327-336.

Markey, K., Reih, S. Y., St. Jean, B., Yakel, E, Xingxing, Y. (2009). Secrets of success: Identifying success factors in institutional repositories. Open Repositories 2009 Conference Proceedings. Retrieved from http://hdl.handle.net/1853/28419

Nicholas, D., Rowlands, I., Watkinson, A., Brown, D., Russell, B., \& Jamali, H. R. (2013). Have digital repositories come of age? The views of library directors. Webology, 10(2), 1-16. Retrieved from http://www.webology.org/2013/v10n2/a111.pdf

Nneka Eke, H. (2011). Digitizing resources for University of Nigeria repository: Process and challenges. Webology, 8(1), 1-19.

Owen, T. M. (2011). Evolution of a digital repository: One institution's experience. Journal of Electronic Resources Librarianship, 23(2), 142-149. http://dx.doi.org/10.1080/1941126X.2011.576959

R Core Team. (2014). R: A Language and Environment for Statistical Computing. R Foundation for Statistical Computing. Vienna, Austria. http://www.r-project.org

Tenopir, C. (2013). Building evidence of the value and impact of library and information services: Methods, metrics and ROI. Evidence Based Library and Information Practice, $8(2), 270-274$.

Top Institutional. (2014). Ranking web of repositories. Retrieved from http://repositories.webometrics.info/en/top_Inst

Tripathi, M., \& Jeevan, V. K. J. (2011). An evaluation of digital libraries and institutional repositories in India. The Journal of Academic Librarianship, 37(6), 543-545. http://dx.doi.org/10.1016/j.acalib.2011.08.012 
UNT (University of North Texas) Open Access Policy. (2012). Open access, self-arching, and long-term digital stewardship for University of North Texas scholarly works. Retrieved from http://openaccess.unt.edu/unt-open-access-policy

Waugh, L., Murray, K., Phillips, M., Belden, D. (2013). UNT Digital Library Value Study Data [Data File]. Retrieved from http://digital.library.unt.edu/ark:/67531/metadc307537/

Yang, Z. Y. \& Li, Y. (2015). University faculty awareness and attitudes towards open access publishing and the institutional repository: A case study. Journal of Librarianship and Scholarly Communication, 3(1). http://dx.doi.org/10.7710/2162-3309.1210 